\title{
A PROVA ESTATíSTICA NA TUTELA COLETIVA DE CONSUMO
}

\author{
THE STATISTICAL PROOF IN COLLECTIVE CONSUMER PROTECTION
}

\author{
Dennis Verbicaro \\ Doutor em Direito do Consumidor pela Universidade de Salamanca (Espanha) \\ Universidade Federal do Pará (UFPA) \\ Centro Universitário do Pará (CESUPA) \\ Belém/PA. Brasil. \\ dennisverbicaro@bol.com.br
}

\begin{abstract}
Janaína do Nascimento Vieira
Mestranda em Direitos Humanos, com ênfase em Direito do Consumidor - UFPA.

Belém/PA. Brasil.

janainanasvieira@gmail.com
\end{abstract}

\begin{abstract}
Resumo: A tutela coletiva de consumo é uma das principais expressões do ideal de solidariedade, sobretudo por apresentar uma nova dimensão social para o processo coletivo e por favorecer a ocupação desse importante espaço político para o consumidor, agora compreendido como categoria. Com o mesmo enfoque, em busca do equilíbrio entre interesses nas relações de consumo, a utilização da prova estatística na tutela coletiva pode surtir reflexos sociais pelo entendimento de que práticas responsáveis de mercado geram estatísticas positivas e condenações menos gravosas às empresas. Assim, analisar-se-á a produção da prova, especialmente a prova estatística para, ao final, identificar a sua influência na defesa coletiva do consumidor, através do método hipotético-dedutivo.
\end{abstract}

Palavras-chave: Tutela coletiva. Prova Estatística. Relações de Consumo.

Abstract: The collective consumer protection is one of the main expressions of solidarity ideal, mainly because it presents a new social dimension to the collective process, but also by favoring the occupation of this important political space for the consumer, now understood as a category. With the same focus, in search of a balance between interests in consumer relations, the use of statistical evidence in collective protection can cause social reflexes by understanding practical market practices that generate positive statistics and less severe condemnations in companies. Thus, the production of proof will be analyzed, especially the statistical proof, to identify the influence of this use in defense of the consumer, by the hypothetical deductive method.

Keywords: Class Actions. Statistical Proof. Consumer relations.

Para citar este artigo (ABNT NBR 6023:2018)

VERBICARO, Dennis; VIEIRA, Janaína do Nascimento. A prova estatística na tutela coletiva de consumo. Revista Thesis Juris - RTJ, São Paulo, v. 9, n. 2, p. 361-379, jul./dez. 2020. http://doi.org/10.5585/rtj.v9i2.17013. 


\section{Introdução}

A pós-modernidade impôs o reconhecimento da igualdade material aos sujeitos pela identificação da diferença, exigindo um novo paradigma do direito privado - O paradigma da Diferença (MARQUES, MIRAGEM, 2012, p.127), pautada no Estado de Bem Estar Social que reconheceu a autoridade do Estado como necessária para proteção dos indivíduos no âmbito das relações sociais e econômicas. No entanto, viu-se a necessidade de compartilhamento dessa autoridade política face da impossibilidade estatal de gerir e garantir a proteção efetiva dos agentes.

A solidariedade foi o ponto de chegada no processo de transição entre o individualismo liberal do direito privado e o pluralismo jurídico voltado para a proteção de grupos e categorias. O Direito do Consumidor sempre esteve na vanguarda dessa transformação ao abraçar o ideal de solidariedade como base de uma tutela normativa mais inclusiva, transindividual e, sobretudo, voltada para a proteção do consumidor como categoria vulnerável nos artigos $5^{\circ}$, XXXII e 170, V, ambos da Constituição Federal, seja no capítulo dos direitos e garantias individuais, seja na estruturação da ordem econômica.

Nesse particular, houve uma legítima preocupação em se compatibilizar a livre iniciativa empresarial com a proteção do consumidor, através do reconhecimento de sua inferioridade econômica nas relações de consumo, enquanto fator legítimo de discriminação, o que justificou a criação de desigualdades jurídicas de tratamento, seja no âmbito da proteção jurídica material, mas também processual e, nesse aspecto, com enfoque na proteção transindividual de seus interesses.

A Lei 8.078/1990 (Código de Defesa do Consumidor) tornou efetiva a proteção constitucional dessa nova categoria jurídica, destacando, no seu art. $1^{\circ}$, a necessidade de equilíbrio entre as partes na relação de consumo através da adoção de postura analítica ao definir regras de conduta, criar conceitos normativos, positivar princípios, bem como ao promover uma profunda transformação no sistema processual brasileiro, seja pela introdução de novos institutos, seja por prestigiar a instrumentalidade das formas, mas principalmente por introduzir um novo modelo de jurisdição civil coletiva para o reconhecimento dos interesses do consumidor em sua feição transindividual.

Assim, muitas mudanças foram trazidas para proteção consumerista, como: a revalorização das ações executivas latu sensu, quando se cria a tutela específica das obrigações de fazer e não fazer (art. 84, CDC); a limitação à interferência de terceiros na lide, com a vedação à denunciação à lide quando prejudicial aos interesses do consumidor (art. 88, CDC), 
solidariedade passiva do agente econômico, foro privilegiado do consumidor, inversão do ônus da prova e, como referido acima, o fortalecimento da tutela coletiva.

No entanto, apesar da importância das ações coletivas, não há no ordenamento jurídico brasileiro um Código de Processo Civil Coletivo que indique um procedimento uniforme. Há sim um conjunto de normas esparsas, como o próprio Código de Defesa do Consumidor, e o uso do Código de Processo Civil, especialmente no que diz respeito à produção de provas.

É inegável afirmar que, no âmbito das ações coletivas, a prova tem um caráter de extrema relevância por repercutir no reconhecimento ou não de um provimento jurisdicional com repercussão transindividual, podendo atingir os interesses de toda a coletividade de consumidores. Por isso, a grande importância do estudo da prova, sejam as consideradas típicas (aquelas expressamente previstas na legislação), ou atípicas (sem previsão normativa).

Como exemplo de prova atípica, a prova estatística apresenta essencial importância aos litígios considerados complexos pela ineficácia das provas consideradas "tradicionais", ou seja, aqueles que se vinculam a fatos passados. Embora pouco utilizada no ordenamento jurídico brasileiro, considerando Arenhart (2019, p.663), a complexidade das lesões que envolvem as demandas coletivas, o que exige respostas que "também demandarão, muitas vezes, análises que probabilidades futuras ou - mesmo quando examinam o passado - imporão a avaliação de um plexo de situações", fundamenta a utilização dessa prova.

O desestímulo de seu uso poderá acarretar na incidência de práticas negativas, não facilmente comprovadas através de provas típicas e "tradicionais", diante de um contexto "em constante processo de mercantilização, fomentado pela desigualdade de condições na escala produtiva dos bens de consumo" (VERBICARO; OHANA, 2020, p.7), evidenciado pelo estabelecimento de uma sociedade em que o ato de consumir ganha centralidade, exaultado pelo consumismo em massa, sendo as marcas e seus simbolismos a representação dos desejos do consumidor (LEAL, 2019, p.198).

Neste sentido, a necessidade de se avaliar o uso da prova estatística como uma ferramenta eficaz na defesa coletiva dos interesses do consumidor justifica-se pelo seu reflexo social na modulação ética do comportamento empresarial, pois se por um lado às avaliações estatísticas são consideradas um meio de prova na busca de garantir a efetividade da tutela judicial, por outro lado, orientam, de modo bastante utilitarista, a atitude empresarial conforme estimativas de perdas e ganhos no processo, podendo também ser usadas para direcionar práticas mercadológicas responsáveis quanto à qualidade e segurança dos produtos e serviços.

Assim, para o desenvolvimento da pesquisa, usou-se o método hipotético-dedutivo, a partir de pesquisa teórico-bibliográfica nacional e estrangeira, sendo, primeiramente, realizado 
um estudo sobre processo coletivo como processo interesse público, com ênfase na defesa do consumidor. Posteriormente, analisou-se a produção da prova estatística para, por fim, identificar sua influência social no equilíbrio mercadológico.

\section{Processo coletivo como processo de interesse público e tutela coletiva de consumo no Brasil}

Quando se analisa processos de caráter coletivo, a concepção construtivista da relação entre direito e sociedade sobrepõe as decisões judiciais por gerar transformações sociais, não apenas quando induzem mudanças na conduta dos grupos e indivíduos diretamente envolvidos no caso, mas também quando produzem transformações indiretas na sociedade (GRAVITO, 2011, p.1669 - 1698). Esses efeitos indiretos incluem consequências diversas que, sem serem definidas ou previstas nas decisões, derivam dela.

Abramovich (2005, p.199) estabelece que, em processos de violação aos direitos econômicos, sociais, culturais e ambientais, de natureza coletiva, o poder judiciário não tem como tarefa projetar políticas públicas, mas sim confrontá-las, assumindo padrões jurídicos aplicáveis e, no caso de haver divergências, reenviar a questão em discussão para o poder pertinente para que ele ajuste a atividade. Portanto, trata-se de litígios de interesse público em razão da projeção coletiva, fática e jurídica da demanda.

Para Salles (2003, p.40 - 41), a expressão “interesse público” faz contraposição ao individual, caracterizado, portanto, como aquele relacionado ao interesse pertencente à generalidade das pessoas em busca da máxima efetividade com orientação finalista dos objetivos sociais nele contidos.

Para Didier Jr e Zaneti Jr (2017, p.39), o interesse público pode ser primário, ou seja, o complexo de interesses coletivos, e secundário, voltados à satisfação do interesse da administração pública. A tutela coletiva está voltada para satisfação do interesse público primário.

Por estar vinculado a interesses da coletividade e pela sua execução envolver diversos poderes, considerando Langford (2009, p.108), há dificuldade de imposição das obrigações positivas uma vez que é discutida a ilegitimidade do judiciário do ponto de vista democrático para impor direitos sociais, bem como, a tarefa institucional do juiz diante da sua incompetência institucional e realização de políticas públicas. Neste sentido, existe um dilema policêntrico face das críticas da justiciabilidade diante da chamada impossibilidade do judiciário em não 
poder e não dever se ocupar de situações que tenham repercussão complexas para além das partes e dos fatos perante o tribunal frente ao caráter coletivo dos direitos sociais.

Para Loiane Verbicaro (2017, p.324 - 333), cabe ao judiciário, como resultado da consolidação do Estado Democrático de Direito, o papel contra majoritário capaz de resguardar os ideais de igualdade, liberdade e dignidade humana. Assim, a judicialização da política representa uma maior interferência do judiciário no espaço de atuação dos poderes políticos do Estado, permitida para assegurar a respeitabilidade dos direitos fundamentais. Aduz ainda que a intervenção do judiciário é complementar e não excludente às vias políticas. Deve representar um reforço à lógica democrática. Quando as questões políticas chegam ao tribunal, exigem uma decisão específica e baseada em princípios para garantir a respeitabilidade à Constituição e aos direitos fundamentais. Não há óbice ao controle de atos políticos pelo judiciário. O problema está em basear esse controle em fundamentos estritamente políticos.

Para Theodoro Jr, Nunes e Bahia (2013, p.136), é necessário somar estratégias além da judicialização, o que possibilitaria que Estado garanta a efetividade aos diretos através de adoção de medidas adequadas de sua implementação progressiva dentro de recursos disponíveis através da razoabilidade.

No que diz respeito à constitucionalização do Estado Social, possibilitou a ampliação das funções jurisdicionais de interesses coletivos antes subjugados, como o equilíbrio das relações de consumo, além de trazer um teor valorativo com objetivo garantir o pleno exercício dos direitos sociais e coletivos tipificados (OLIVEIRA, 1997, p.11). Para Langford (2009, p.106), tal constitucionalização fortaleceu a discussão sobre os direitos sociais e, consequentemente, sua defesa. Apesar de algumas leis vinculadas ao microssistema da tutela coletiva serem anteriores a Constituição da República de 1988, pode-se afirmar que a norma constitucional atribuiu um caráter valorativo as normas processuais, ratificou a tutela de direitos coletivos em sentido amplo, em seus artigos $5^{\circ}$, XXI, LXX, LXXIII; $8^{\circ}$, III; 37, § $4^{\circ}$; 129, III; 216 e; 225, dentre outros, e inaugurou proteção do consumidor como direito fundamental quando, nos seus artigos $5^{\circ}$, inciso XXXII, e 170, outorgou caráter de protagonismo constitucional.

O microssistema processual coletivo evidencia e caracteriza o policentrismo e têm por base a harmonização sistemática entre várias leis. É um diálogo das fontes articulados entre Constituição federal, Código de Processo Civil, Código de Defesa do Consumidor, Lei de Ação Popular, Lei da Ação Civil Pública, Lei de Improbidade Administrativa, Lei de Mandado de Segurança e demais leis avulsas (DIDIER JR, ZANETI JR, 2017, p.56). 
A Lei da Ação Popular (Lei 4.717/1965) foi à primeira norma a destinar uma tutela especifica aos direitos coletivos. Quase 20 anos depois, com a Lei 7.347/1985, o ordenamento jurídico brasileiro avançou em razão da criação uma ação judicial especifica para a defesa de direitos metaindividuais - difusos e coletivos (ZAVASKI, 2007, p.37). Ademais, a Lei de Improbidade Administrativa (Lei 8.429/1992) também abarca direitos iminentemente coletivos.

O Código de Defesa do Consumidor (Lei 8.078/1990) ampliou o conceito de consumidor ao vinculá-lo, no seu art. $2^{\circ}$, parágrafo único, e art. 29, a coletividade. Assim, tal Código especificou sua definição em difuso, coletivo sentido estritos e individuais homogêneos.

O interesse difuso é aquele que não permite a identificação de seus sujeitos titulares, que são indeterminados e não permitem o fracionamento do objeto. Como exemplo da manifestação da tutela difusa, pode-se citar a oferta e publicidade (artigos. 30 a 38 do CDC), o que não exige o fato do consumidor se sentir ou não prejudicado, sendo qualquer legitimado extraordinário competente para defesa, conforme artigo 81 e 82 CDC. São abstratos, indeterminados, indivisíveis e internamente litigiosos (VERBICARO, 2017, p.334).

O direito coletivo em sentido estrito surge no artigo 129, III, do CF. Representa a síntese dos interesses de um grupo, passíveis de identificação, quanto à apuração do dano e da responsabilidade. Haverá o reconhecimento de uma relação jurídica base, ou seja, limitação natural ao alcance da tutela. Portanto, sua principal distinção "entre os interesses difusos e os coletivos em sentido estrito é a determinabilidade dos sujeitos" (VERBICARO, 2017, p.339).

Os interesses individuais homogêneos constituem uma inovação jurídica do CDC, nos artigos 91 a 93. Na sua essência são individuais, podendo ser coletivizado pela instrumentalização pela via coletiva e através do legitimado extraordinário. $\mathrm{O}$ caráter transindividual limita-se ao aspecto processual, ou seja, "existirá sob o ponto de vista formalinstrumental" (VERBICARO, 2017, p.327).

Para Verbicaro (2017, p.341), a coletivização de um interesse que, originalmente, era meramente individual subjetivo, trará vantagens ao consumidor, uma vez que a pluralidade de consumidores lesados dará melhores condições de influir de modo decisivo na própria convicção do magistrado.

Para Vitorelli (2015, p.98), o conceito legal de direitos transindividuais, presente no Código de Defesa do Consumidor, é insuficiente em razão de ignorar que os litígios coletivos têm graus variados de complexidade e de conflituosidade, o que impossibilita que todos eles sejam tratados da mesma forma, sob o risco de se utilizar recursos desnecessários a casos simples e/ou simplificar indevidamente casos complexos, além de se suprimir indevidamente divergências sociais legítimas. 
Assim, para o autor, a solução proposta é a conceituação dos direitos transindividuais em três categorias diversas, atribuindo sua titularidade a uma sociedade que é constituída sob o prisma do litígio transindividual, são elas: 1- Litígios transindividuais globais, ou seja, para violações que não atinjam, de modo particular, a qualquer indivíduo, sendo representada pelo Estado nacional titular do território em que ocorreu a lesão; 2- Litígios transindividuais locais, isto é, têm lugar no contexto de violações que atinjam de modo específico, a pessoas que integram uma sociedade altamente coesa, unida por laços identitários de solidariedade social, emocional e territorial; 3- Litígios transindividuais irradiados, ou seja, são litígios que envolvem a lesão a direitos transindividuais que interessam de modo desigual e variável a distintos segmentos sociais, em alto grau de conflituosidade. Portanto, para Vitorelli (2015, p.99), "a titularidade do direito material subjacente é atribuída, em graus variados, aos indivíduos que compõem a sociedade, de modo diretamente proporcional à gravidade da lesão experimentada". Neste sentido, todos poderão ser enquadrados em quaisquer das três categorias, conforme o perfil da lesão e o tipo de sociedade considerando o direito atribuído.

Com legitimidade ativa ope legis, as associações civis, ao lado do Ministério Público, da Defensoria Pública, da União, os Estados, o Distrito Federal, Municípios, Autarquias, Empresas públicas, Fundações ou Sociedades de Economia Mista, possuem legitimidade para propor ações coletivas, desde que preenchidos os requisitos legais previstos nas alíneas "a" e "b" do artigo 5, inciso V, da Lei 7347/1985 (VERBICARO, COSTA, 2018, p.76). No entanto, após análise sobre atuação dos legitimados ativos em promover ação coletiva, em especial as Associações Representativas de Direito do Consumidor, observou escassez na promoção de tutela coletiva, extraprocessual ${ }^{1}$ e processual $^{2}$, em conflitos de consumo.

Para a tutela coletiva alcançar a efetividade, o Código de Processo Civil é de extrema importância diante da omissão de normatividade específica sobre o tema. A inexistência de Código de Processo Coletivo para indicar um procedimento uniforme na tutela coletiva exigiu a utilização do Código de Processo Civil, especialmente na produção de prova.

A criação de mecanismos jurídicos que visam facilitar a produção probatória, especialmente em caráter coletivo, conforme objeto de estudo, é de grande relevância prática, como se verá no tópico a seguir.

\footnotetext{
${ }^{1}$ Para Verbicaro e Costa $(2018$, p.79), “apesar de o número ser considerado pequeno, o que poderia ser compensado por meio da atuação ativa dessas associações, a informação prestada pela Gerência de Educação e Projetos do órgão administrativo adverte que a atuação destas se restringe apenas a participação - de indivíduos que se intitulam como representante - em eventos organizados pelo PROCON, não havendo registro de representações, denúncias ou solicitação de parcerias de quaisquer associações".

${ }^{2}$ No âmbito da atuação judicial, foi realizada uma pesquisa processual de dados no Poder Judiciário Estadual, além da verificação nos processos físicos no Fórum Cível da Comarca de Belém, sendo encontrados apenas três processos ajuizados por Associações Representativas de defesa do consumidor, ressaltando que uma única associação teria sede no Estado do Pará (VERBICARO, COSTA, 2018, p. 80).
} 


\section{A Cooperação e a utilização da prova estatística}

\subsection{A Cooperação e a distribuição do ônus da prova}

A cooperação está disposta no art. $6^{\circ}$ do Código de Processo Civil como um dos princípios estruturantes do processo civil e se desenvolve através da participação de todos os sujeitos processuais em toda atividade jurisdicional. A cooperação pressupõe deveres entre as partes, como o esclarecimento, consulta prevenção e auxílio, destacando, nesse ultimo caso, ônus da prova, em observância ao art. 373, parágrafo $1^{\circ}$ e $2^{\circ}$ do CPC (BUENO, 2018, p.401 402).

Figueiredo Filho e Mouzalas (2015) afirmam que a cooperação cria uma atmosfera dialogal, sendo a cooperação intersubjetiva um marco estrutural do processo por ter como objetivo a prática do juiz colaborante como a própria personificação "dos anseios democráticos e participativos de um Estado democrático de Direito, de modo a transformar o processo civil em uma comunidade de trabalho e a responsabilizar as partes e o tribunal pelos seus resultados" (FIGUEIREDO FILHO, MOUZALAS, 2015, p.367).

A produção de prova é uma incidência do princípio da cooperação no processo. A prova, mais do que parte do procedimento, é um sistêmico instrumento de controle do raciocínio judicial, de refreamento de arbitrariedade e de efetivação do devido processo legal (DIAS et $a l ., 2019$, p.239). A prova é o meio de confirmação ou negativa da hipótese, sendo "um teste de coerência entre a formulação e o provável suporte fático da demanda" (DIAS et al., 2019, p.241). Em outras palavras, a prova disponibilizará ao juízo informações para identificar a veracidade das alegações fornecidas pelas partes (RODRIGUES, 2018, p.259).

Nesse sentido, seja em caráter individual ou coletivo, a prova tem uma essencial importância em garantir o acesso à justiça. A distribuição dinâmica do ônus da prova está prevista no art. 373 do CPC, podendo ser transportada para proteção de interesses transindividuais como forma de garantir maior efetividade à tutela de seus direitos.

A teoria dinâmica do ônus da prova diz respeito à possibilidade do julgador distribuir a ônus de maneira diversa, principalmente naquelas situações em que uma das partes é considerada hipossuficiente, sendo atribuída a parte de detém de melhores condições para produzir determinada prova.

É fato que o legitimado ativo coletivo por vezes não dispõe de meios de prova para produção de suas alegações, pela complexidade da demanda e pela restritabilidade da informação. A distribuição dinâmica do ônus da prova nas ações coletivas está diretamente 
relacionada com o princípio da cooperação, como forma de possibilitar que nenhuma das partes seja prejudicada na demanda, sobretudo quando não apresentam meios necessários para produzi-las, o que causaria desequilíbrio na relação (RODRIGUES, 2018, p.271-273). Assim, busca-se a união de esforços entre as partes e o magistrado para melhor solução da lide através da produção de qualquer meio de prova, sejam aquela considerada típica ou atípica, como a prova estatística, conforme melhor explicado a seguir.

\subsection{Aspectos gerais sobre a prova estatística}

A estatística é um ramo da matemática vinculada à coleta, organização, registro e estudo por amostras sobre informações uteis relacionadas ao problema em análise. Para gozar de credibilidade, deve abarcar um sistema metodológico confiável. A sua viabilidade, como prova processual, está assentada na qualidade da inferência e das informações colhidas (ARENHART, 2019, p.669).

No que diz respeito à classificação da prova estatística, pode utilizar dois critérios: a) origem das informações coletadas e b) o percentual do grupo previamente examinado. Com base nesses dois pontos, pode-se dividir a prova estatística em quatro modalidades: a) O censo sobre declarações dos sujeitos pertencentes ao universo examinado; b) o que não envolve declarações ou impressões pessoais dos membros do universo pesquisado; c) a pesquisa por amostragem envolvendo declarações ou impressões pessoais dos sujeitos pertencentes ao universo pesquisado; d) a pesquisa por amostragem não envolvendo declarações ou impressões pessoais dos sujeitos pertencentes ao universo pesquisado (ARENHART, 2019, p. 669 - 670).

Utiliza-se também como classificação da prova estatística as consideradas descritivas e inferenciais. A primeira resume e processa dados para convertê-los em informações. Já a segunda, tem por objeto transformar a informação para fazer previsões e estimativas (RUEDA, SERRANO, 2014, p.118).

Ademais, a prova estatística pode ser categorizada em documental, pericial ou prova autônoma. Neste ultimo caso, transforma-se em meio de verificação pelo método de averiguação e comparação (RUEDA, SERRANO, 2014, p.121-125).

Quanto a sua produção processual, considerando o Manual for Complex Litigation, aduzido por Vitorelli (2019b, p.6), o juiz ao utilizar a prova estatística no processo deve observar as seguintes orientações: supervisionar o método, determinar parâmetros conforme estatísticas reconhecidas pela comunidade científica, atentar ao procedimento de entrevista, garantir a elaboração de relatório adequado, definir indicadores objetivamente verificados, 
todos com apoio de perito, para indicar o valor da prova. Destaca ainda que é possível a utilização de banco de dados disponíveis em bases externas, como registros públicos e dados epidemiológicos. Ainda, conforme a Regra 703 da Federal Rules of Evidence, dispõe que o perito pode expressar opiniões com base na prova estatística ${ }^{3}$.

$\mathrm{Na}$ Colômbia, inclusive, é admitida a utilização de prova estatística em ação coletiva face à complexidade das lesões ocorridas, conforme afirma art. 28, da Lei Colombiana 472, de $1998^{4}$ (ARENHART, 2019, p.667).

No entanto, quando se analisa a prova estatística em conjunto com demais provas, a sua aceitação é de $65 \%$ nas decisões. Aquelas analisadas de forma isolada apresentam sua utilização em caráter inferir a 10\% (VITORELLI, 2019a, p.6). Trata-se, portanto, da imposição de forma implícita do juízo subjetivo de probabilidade do magistrado.

Vale citar a análise de Shmalbeck (1986, p.222 - 229) sobre a prova estatística no caso hipotético Red Cab Company: Após a ocorrência de um acidente em razão da direção imprudente de um motorista de táxi, não havia provas para identificação do motorista, apenas critérios estatísticos. Viu-se que $60 \%$ da frota daquela noite, naquela zona, era da Red Cab Company, por isso, considerando critérios de tráfego, número de violações de motoristas pela companhia, utilizou-se a prova estatística para vincular a companhia de táxi ao evento danoso.

No caso em discussão, observaram-se três críticas para utilização da prova estatística: o nível de confiança, ou seja, não se tem certeza sobre a estimativa de $60 \%$ da frota de circulação; a aplicação da probabilidade parcial para produzir a estimativa do todo e a desconfiança nas evidências estatísticas.

Ao observar as críticas, é nítido que estão vinculadas aos critérios metodológicos de produção dos dados. É fato que a prova estatística apresenta sim uma estimativa de erro, como em todas as demais provas. Mas, considerando Shmalbeck (1986, p.235), devem-se buscar nos autos as evidências relevantes, sejam estatísticas ou não.

Para Mello (2009, p.162-163), o fato de não haver no ordenamento jurídico uma orientação sobre a utilização da prova estatística não deve ser motivo para impedimento, uma vez que o próprio Código de Processo Civil não apresenta rol taxativo na especificação das provas admitidas no processo. Afirma ainda que a precisão dos dados na estatística depende da

\footnotetext{
${ }^{3}$ No original, em inglês, Regra 703: "An expert may base an opinion on facts or data in the case that the expert has been made aware of or personally observed. If experts in the particular field would reasonably rely on those kinds of facts or data in forming an opinion on the subject, they need not be admissible for the opinion to be admitted. But if the facts or data would otherwise be inadmissible, the proponent of the opinion may disclose them to the jury only if their probative value in helping the jury evaluate the opinion substantially outweighs their prejudicial effect."

${ }^{4}$ No original, em espanhol, Art. 28 - Ley 472/98: “El juez podrá ordenar o practicar cualquier prueba conducente, incluida la presentación de estadísticas provenientes de fuentes que ofrezcan credibilidade".
} 
forma como ocorreu sua coleta, o que não impede a existência de margem de erro que também deverá ser considerada, razão pelo qual não desqualifica a sua utilização.

No entanto, evidências empíricas demonstram que os juízes, usualmente, concluem sobre a relevância da prova estatística, relacionando-a com outras provas e com o grau de confiabilidade de cada uma delas, conforme o que é determinado pela criação de uma história mental, sendo "aquilo que se encaixa na história é reputado provável, ordinário, enquanto o que não se encaixa é visto como improvável, extraordinário" (VITORELLI, 2019a, p.5). Esquecem, portanto, que todo raciocínio probatório inclui análises probabilísticas para reduzir a credibilidade estatística pura, tarifando-a negativamente ${ }^{5}$.

Ao contrário, a admissibilidade da prova estatística deverá seguir os critérios definidos para produção conforme as demais provas. O próprio magistrado, através da distribuição dinâmica da prova, deverá produzi-la e se lançar das "provas de certeza” ou provas típicas para as disponíveis naquele caso em análise (ARENHART, 2019, p. 672, 674 - 675).

Considerando Vitorelli (2019a, p.12-13), é necessário fomentar um diálogo entre as partes, em especial juristas e estatísticos, para definir os critérios da utilização dessa prova específica no processo, identificando os direitos que podem ser definidos por estatísticas; os métodos estatísticos confiáveis em observância aos casos; o grau de probabilidade exigível; o modo de produção da prova estatística; a maneira pela qual as partes podem intervir na análise realizada pelo perito, quando produzida pelo juízo; além de como os juízes deverão analisar as estatísticas para decisão.

A utilização da prova estatística em processo coletivo trata-se, portanto, de um nítido reflexo do princípio da cooperação na produção de prova em busca da melhor solução desse litígio, sobretudo no âmbito das relações de consumo, que favorece o manejo de um sofisticado modelo de jurisdição civil coletiva, em atenção distribuição dinâmica do ônus probatório estabelecida pelo CPC.

\footnotetext{
${ }^{5}$ Vitorelli (2019a, p.11) confirma a assertiva ao estabelecer que "muitas vezes o raciocínio probatório inclui generalizações implícitas quanto a um conjunto de situações que envolvem aquela prova, não relacionados ao caso em exame. Da mesma forma que estatísticas dependem da população analisada, não do caso singular, a credibilidade das provas e, com isso, a decisão, também depende de generalizações a respeito da população de circunstâncias que cercam aquele caso, ou aquele tipo de caso, não apenas do caso em si e das provas que dizem respeito diretamente a ele".
} 


\section{A Construção do Ideal de Solidariedade nas Relações de Consumo através da utilização da prova estatística na tutela coletiva}

$\mathrm{Na}$ modernidade, sustentavam-se duas maneiras de se conhecer a realidade e atuar socialmente no mundo, também denominadas paradigmas epistemológicos e sociais (SANTOS, 2002, p.75): 1) O conhecimento-regulação e 2) O conhecimento-emancipação. A partir desses conceitos sociológicos, Verbicaro (2017, p.23 - 98) explica o enquadramento do Direito do Consumidor nesse contexto de transição de paradigmas.

Nesse sentido, o conhecimento-regulação teria por base uma sociedade indolente, cujo monopólio da produção da norma e de proteção social seria do Estado com base no liberalismo político-econômico e no individualismo jurídico. Quando uma sociedade opta por se afastar do âmbito das deliberações políticas e passa a transferir aos seus representantes políticos tal responsabilidade, o efeito imediato é a existência de uma cidadania débil e da própria incapacidade de indignação com a degeneração de seus direitos (VERBICARO, 2017, p.23 98).

O desafio é a reinvenção através da transição paradigmática do conhecimento-regulação ao conhecimento emancipação, onde o Estado reconhece suas lacunas e a própria sociedade, através da participação ativa, privilegia a ideia de solidariedade. O ponto da ignorância passa a não ser não mais o caos normativo, mas o colonialismo (individualismo jurídico, liberalismo político, a difusão de bravatas ideológicas) e o ponto do conhecimento será a solidariedade, onde o ser humano é visto como sujeito de direitos, resgatando suas obrigações cívicas perante o grupo e perante si mesmo.

A solidariedade defendida não se limita ao conceito de conduta beneficente ou ajuda assistencial, mas numa mudança de consciência moral. Neste contexto, a própria efetividade do direito é colocada em dúvida quando suas normas são concebidas sem eficácia social e validez ética. O conhecimento jurídico não deve ser linear, "pois nas diferentes culturas, ele foi feito de progressos e recuos, sendo o conceito de segurança jurídica variável nessa evolução" (VERBICARO, 2017, p.69). Assim, a norma deve satisfazer o valor moral e resolver conflitos sociais de maneira justa e satisfatória para garantir a harmonia da coletividade.

O Direito do Consumidor é a expressão do ideal de solidariedade, quando, em seu Código, privilegia o pluralismo jurídico ao criar novos espaços políticos de deliberação, através da Política Nacional das Relações de Consumo, fontes principiológicas, o que relativiza as fontes estatais, fortalece a tutela de interesses transindividuais e o compartilhamento da autoridade política. No último caso, o compromisso para proteção dos direitos dos 
consumidores é tripartido entre sociedade, Estado e empresas. O Estado passa a ser o mediador entre os interesses mercadológicos do fornecedor e a categorias de consumidores.

Nas relações de consumo, pode-se caracterizar uma relação entre dois grupos, os consumidores, artigos $2^{\circ}$ e 29 do CDC, e fornecedores, art. $3^{\circ}$ do CDC. Os consumidores são considerados vulneráveis na relação diante da constante propensão de sofrer, seja no âmbito individual e coletivo. $\mathrm{O}$ fornecedor, de outro lado, é toda pessoa física ou jurídica, pública e privada, nacional ou estrangeira, bem como os entes despersonalizados, que desenvolvem atividades de produção, montagem, criação, importação, exportação, distribuição ou comercialização, dentre outras atividades, de produtos ou serviços ${ }^{6}$. Tal conceito tem caráter eminentemente exemplificativo, o que não impede a caracterização de novos atores como fornecedores, como, por exemplo, o provedor de aplicação na economia de compartilhamento (VERBICARO, VIEIRA, 2020, p.8), plataformas de $e$-commerce, redes sociais e etc.

O fortalecimento do ideal de solidariedade nas relações de consumo pressupõe a criação de desigualdades jurídicas em favor do consumidor, a realização da cidadania instrumental no processo deliberativo pelos consumidores, não apenas de forma individual, mas, sobretudo coletiva, a participação do Estado como mediador responsável nesse processo de harmonização de interesses divergentes, bem como, quando se analisa o comportamento das empresas, a mudança do enfoque no exercício da sua atividade conforme convicções do capitalismo predatório para o capitalismo responsável ${ }^{7}$. Trata-se, portanto, da cooperação em busca da satisfação do interesse público no âmbito coletivo, sob o prisma consumerista.

Em atenção à cooperação supracitada, a produção da prova estatística em processo coletivo tem como finalidade alcançar soluções em situações de difícil dilação probatória, pelo iminente risco social e em proteção as gerações atuais e futuras. A exclusão de prova estatística é um estímulo negativo ao mercado por ratificar comportamentos predatórios à sociedade, “consubstanciados em condutas que não possam ser comprovados por evidências diretas, tradicionais" (VITORELLI, 2019a, p.12).

É possível citar como casos que envolvem discussão da prova estatística relacionada com relações de consumo os processos contra grandes empresas de medicamentos americanos em razão da utilização de dietestilbestrol - DES. Identificou-se que a substância utilizada possibilitaria a incidência de câncer em filhas de mães que utilizaram o medicamento durante

\footnotetext{
${ }^{6}$ Cf. LEI 8078/1990, artigo $3^{\circ}$ do CDC.

${ }^{7}$ Para Paul Zak (2012, p.157 - 183), o mercado está além de práticas predatórias e exploratórias. São relações sociais que aumentam a lucratividade por práticas responsáveis de mercado. O autor evidencia o conceito de mercado moral, ao defender que a conexão (trocas de ideias e interação), confiança, foco na qualidade e serviço, não no dinheiro em si, geram benefícios para todas as partes por causar um ciclo virtuosos de confiança e reciprocidade, o que leva inclusive a expansão econômica.
} 
a gravidez. Com apenas a indicação do fabricante poder-se-ia responsabilizá-lo (BROOK, 1985, p.305-308).

No entanto, a dificuldade no caso em discussão foi justamente a ausência de evidência disponível para relacionar o polo passivo ao dano. Neste sentido, mais de mil ações de DES passaram a identificar as grandes empresas de medicamentos no polo passivo com base na prova estatística em razão da sua participação no comércio de medicamentos (BROOK, 1985, p.305308). As decisões seguiram a mesma perspectiva em alocar a solução pro rata de acordo com o mercado.

De outro modo, a utilização da prova estatística está além da persecução da melhor decisão no processo para partes, mas, sim, tem reflexo social por abarcar o interesse público nas tutelas coletivas ${ }^{8}$ e ainda por forçar ao fornecedor a agir em conduta compatível com o desenvolvimento do ideal de solidariedade nas relações de consumo pela simples mudança no agir predatório das empresas por práticas mais responsáveis.

O ideal de solidariedade discutido busca o equilíbrio nas relações do consumo através de práticas responsáveis pelos três agentes que compõe o compromisso tripartido das obrigações. A sociedade deve desvincular-se de práticas indolentes e individualistas para exercer a defesa de seus direitos de maneira transindividual, sendo, portanto, a tutela coletiva um reflexo desse ideal. O Estado, não mais como principal agente, mas o grande mediador dos interesses sociais e mercadológicos, precisa, por outro lado, incentivar políticas voltadas à educação para consumo e a participação ativa da sociedade, englobando, aqui, o incentivo a medidas sociais e judiciais. Por fim, as empresas, ao entenderem que o mercado é um contrato social, devem realizar a correlação entre o comportamento moral, a eficiência e lucratividade nas transações, mesclando o interesse individual com o bem social (ZAK, 2012, p.159).

A utilização da prova estatística, portanto, podem refletir no processo práticas predatórias ou responsáveis de mercado. Como se viu, provas consideradas "tradicionais" são insuficientes para tutelar litígios de lesões complexas, como nas tutelas coletivas. Ao serem produzidas, as empresas serão diferenciadas e beneficiadas conforme o seu ideal capitalista. Consequentemente, a partir do momento em que o mercado sentir o reflexo negativo de ações exploratórias, será entendido a necessidade de mudança. Logicamente, as ações individuais não causam o impacto social. Por isso, a frisa-se a importância da utilização de prova estatística na tutela coletiva.

\footnotetext{
${ }^{8}$ Como exemplo, pode-se citar a utilização de prova estatística contra práticas discriminatórias, seja na relação de trabalho e emprego, na União Europeia, nas Diretivas 2000/43/CE e 2000/78/CE, seja em ações criminais, nas Cortes Americanas, como, por exemplo, para provar a influência da condição racial nas penas de morte (ARENHART, 2019, p. 666).
} 


\section{Conclusão}

É fato que a análise utilitarista da atuação do judiciário pelas empresas influenciará no seu agir mercadológico. No Brasil, o agente econômico, litigante habitual, é quem verdadeiramente se beneficia das incertezas do sistema jurídico brasileiro por ter condições que moldar, conforme os seus interesses, o perfil jurisprudencial que lhe apetece, beneficiando-se da falta de estabilidade do sistema jurídico (SILVA; GÓES, 2019, p.54).

Verbicaro, Silva e Leal (2017, p. 14) observam que causas relacionadas com relações de consumo no judiciário estão eivadas de "preconceitos e análises rasas, baseadas em um desvirtuamento da lógica e sem estudo empíricos de base". A pretensão consumerista segue uma premissa de desmerecimento em razão da massificação das demandas e do entendimento que ações consumeristas seguem pretensões aventureiras, o que supostamente justificaria os parâmetros indenizatórios insultuosos e o não reconhecimento de bens jurídicos lesados pelo judiciário (VERBICARO; SILVA; LEAL, 2017, p.13), incentivando, portanto, ao mercado a práticas lesivas para o consumidor.

Para efetivar uma relação de equilíbrio e harmonia através da confiança e da conexão, as empresas não devem preocupar-se apenas com o benefício quantitativo, e sim em realizar com eficiência bons produtos e serviços, sendo o aumento da renda uma consequência inequívoca No entanto, questiona-se como exigir o desenvolvimento de práticas conscientes dos fornecedores em um contexto de mercado predatório?

A tutela processual consumerista como um reflexo do ideial de solidariedade amplia a legitimidade, enfatiza a participação social e proteção coletiva através da prática harmoniosa entre seus agentes. É inequívoco entender que a ação desencorajadora a tutela consumerista pelo judiciário estimula práticas mercadológicas predatórias.

Como se viu, a atuação do judiciário é essencial ao estabelecimento do equilíbrio social e mercadológico. Para Silva e Góes (2019, p.47), o sistema jurídico existe para garantir às pessoas decisões dentro de um campo razoável de segurança. Neste sentido, as leis, costumes, regimentos, decisões judiciais e as normas são parâmetros de conduta, gerais ou específicos, para definição de práticas, sendo razoável esperar que as pessoas ajam de acordo com tais parâmetros. $\mathrm{O}$ mercado segue tal premissa ao realizar estratégias mercadológicas, tendo como um dos eixos a análise jurisprudencial.

O ativismo do consumidor e seu empoderamento importa no exercício qualificado da liberdade de escolha, o que, por sua vez, repercute na adoção de práticas empresariais responsáveis no esforço de autopreservação em ambiente mercadológico competitivo. No 
entanto, não se pode ignorar a atuação do judiciário no permanente processo de estabilização do equilíbrio mercadológico entre consumidores e fornecedores, através, por exemplo, do uso da prova estatística nas ações coletivas.

A prova estatística na tutela coletiva busca garantir a tutela judicial a demandas de alta complexidade e de difícil dilação probatória. O Tribunal Europeu de Direitos Humanos, no caso Hoogendijk vs. Holanda, aludiu à produção de prova estatística ao evidenciar a possibilidade de discriminação sexual pelo Estado (ARENHART, 2019, p.667), o que exigiu condutas positivas para combater tal prática. De modo semelhante:

Em Wal-Mart Stores, Inc. v. Dukes37, estudos estatísticos foram utilizados para demonstrar que mulheres não tinham as mesmas oportunidades que homens em promoções para cargos de gerência na companhia e que, se isso ocorria em todo o país, não poderia ser justificado pelas condutas individuais dos superiores hierárquicos de cada uma das vítimas, mas por uma cultura empresarial disseminada. Como se percebe, a única forma de se fazer a passagem entre a negativa de oportunidades para algumas mulheres e a comprovação de uma cultura empresarial de discriminação, sem avaliar as carreiras de cada uma das mulheres do maior empregador dos Estados Unidos, é por intermédio de estatísticas (VITORELLI, 2019a, p. 6).

Nas relações de consumo, a utilização da prova estatística e, consequente, responsabilidade civil em massa por prática predatória, fazem com que potenciais infratores se sintam desencorajados a praticar condutas ilícitas coletivas e resistam à tentação de obter lucros fáceis em detrimento de direitos e interesses da coletividade.

Em contraponto a atuação muitas vezes desairosa do judiciário em relação à proteção do direito do consumidor supramencionada, a própria Constituição Federal enfatiza a necessidade de uma ação conjunta entre a livre iniciativa e a proteção do consumidor, inclusive através de procedimentos processuais. A utilização da prova estatística nos processos coletivos de consumo evidência quais empresas agem de forma responsável e predatória, além de aguçar o mercado a atuar de forma solidária em atenção ao equilíbrio, harmonia e boa-fé.

Como afirmam Akerlof e Shiller (2016, p.176), empresas podem agir unicamente em atenção ao seu benefício ou através do benefício compartilhado entre o seu lucro e a proteção dos consumidores, dependerá de como se dará o incentivo econômico, social e judicial diante de suas práticas.

De outro modo, no atual contexto de consumo cada vez mais identitário, marcado pela mudança do padrão analógico para digital, em que o consumidor vem aprimorando sua capacidade seletiva no mercado, a prova estatística também funciona como critério objetivo e imediato para a avaliação de desempenho ética dos fornecedores, sendo trunfo importante para o exercício qualificado da liberdade de escolha do consumidor, como também para a 
VERBICARO, Dennis; VIEIRA, Janaína do Nascimento. A prova estatística na tutela coletiva de consumo

identificação dos empresários que ainda insistem no modelo de capitalismo predatório e que, portanto, estarão fadados ao desaparecimento.

Esse desaparecimento será inevitável num ambiente altamente competitivo que o modelo de consumo contemporâneo impõe, em que as plataformas eletrônicas, o comércio eletrônico, a economia de compartilhamento, as redes sociais e a inteligência artificial podem, a um só tempo, gerar a fidelidade do consumidor em relação a uma marca, mas também provocar a aversão imediata, gerando a irrelevância do empresário a médio e longo prazo.

É justamente esse o empoderamento pretendido para o consumidor, que terá na utilização da prova estatística pelos legitimados extraordinários da tutela coletiva não apenas um elemento de convicção importante para infirmar a tese da inicial perante o judiciário, mas também indicativo de como corrigir os desvios de comportamento do empresarial, no plano social.

\section{Referências}

ABRAMOVICH, Victor E. Linhas de trabalho em direitos econômicos, sociais e culturais: instrumentos e aliados. SUR. Revista Internacional de Direitos Humanos, n. 2, p. 188-223, 2005. Disponível em: www.conectas.org/pt/acoes/sur/edicao/2. Acesso em: 04 jan 2020.

AKERLOF, George A; SHILLER, Robert J. Pescando Tolos: a economia da manipulação e fraude. Rio de Janeiro: Alta Books, 2016.

ARENHART, Sergio Cruz. A prova estatística e sua utilização em litígios complexos. Revista Direito e Práxis. Rio de Janeiro, v. 10, n. 1, p.661-677, 2019.

BROOK, James. The Use of Statistical Evidence of Identification in Civil Litigation: Well-Worn hypotheticals, Real Cases, and Controversy. New York Law School, New York, 1985. Disponível em: digitalcommons.nyls.edu. Acesso em: 18 jan 2020.

BUENO, Cassio Scarpinella. Curso sistematizado de direito processual civil: teoria geral do direito processual civil. parte geral do código de processo civil. v. 1. 9. ed. São Paulo: Saraivajur, 2018.

DIAS, Jean Carlos; MOUTA, José Henrique; SILVA, Michel Ferro; SILVA, Adelvan Olivério; HOMCI, Arthur Laércio; PEREIRA, Bernardo Augusto da Costa. Curso de Processo Civil Processo do Conhecimento: revista, ampliada e atualizada conforme a lei. 13.793/2019. 2. ed. Rio de Janeiro: Lumen Juris, 2019.

DIDIER JR, Fredie; ZANETI JR., Hermes. Curso de direito processual civil: processo coletivo. v. 4. Salvador: JusPODIUM, 2017.

FIGUEIREDO FILHO, Eduardo Augusto Madruga de; MOUZALAS, Rinaldo. Cooperação e vedação às decisões por emboscada (ambush decision). In: MACEDO, Lucas Baril de; 
VERBICARO, Dennis; VIEIRA, Janaína do Nascimento. A prova estatística na tutela coletiva de consumo

PEIXOTO, Ravi; FREIRE, Alexandre (org.). Coleção Novo CPC - Parte Geral. v. 1. São Paulo: JusPODIVM, 2015.

GRAVITO, César Rodrigues. Beyond the courtroom: The impact of judicial activism on socioeconomic rights in Latin America. Texas Law Review, n. 89, p. 1669-1698, 2011.

LANGFORD, Malcolm. Judicialização dos direitos econômicos, sociais e culturais no âmbito nacional: uma análise socio-jurídica. SUR. Revista Internacional de Direitos Humanos, n. 11, p. 99-133, dez. 2009. Disponível em: www.conectas.org/pt/acoes/sur/edicao/11. Acesso em: 04 jan. 2020.

LEAL, Augusto Antônio Fontanive. Personalização, consumo e transtornos ambientais. Prisma Jurídico, São Paulo, v. 18, n. 2, p. 189-207, jul./dez. 2019.

MARQUES, Claudia Lima. MIRAGEM, Bruno. O novo direito privado e a proteção dos vulneráveis. São Paulo: Revista dos Tribunais, 2012.

MELLO, Mauricio Correa. A prova da discriminação por meio da estatística. Revista TRT $1^{\text {a }}$ Região, Brasília, v. 15/18, p. 157 - 164. 2006/2009.

OLIVEIRA, Carlos Alberto Álvaro de. Do formalismo no processo civil. São Paulo: Saraiva, 1997.

RODRIGUES, Janaína Eitropio Oliveira. A distribuição dinâmica do ônus da prova do Código de Processo Civil de 2015 como efetivação do acesso à justiça nas ações coletivas. In: OLIVERIO, Adelvan; HOMCI, Arthur Laércio; MENDES NETO, João Paulo. Direito Processual: inovações e perspectivas. Rio de Janeiro: Lumen Juris, 2018.

RUEDA, Álvaro de Jesus Yañez; SERRANO, Cristian Eduardo Laguado. La prueba estadística ante los tribunales internacionales. Revista Academia \& Derecho, anõ 5, n. 9, jul./dic.2014.

SALLES, Carlos Alberto. Processo civil de interesse público. In: SALLES, Carlos Alberto (org). Processo Civil e Interesse Público: o processo como instrumento de defesa social. São Paulo: Revista dos Tribunais, 2003.

SANTOS, Boaventura Sousa. Crítica da Razão Indolente: contra o desperdício da experiência. 2. ed. Porto: Edições Afrontamento, 2002.

SCHMALBECK, Richard. The trouble with statistical evidence. Law and Contemporary Problems. v. 49, n. 3, 1986.

SILVA, Arthur Laércio Homci da Costa; GÓES, Gisele Santos Fernandes. A quem interessa o caos interpretativo na solução judicial de demandas consumeristas de massa no Brasil. In: XXVII Congresso Nacional do CONPEDI de Belém. Anais [...]. Belém/PA: CESUPA, 2019.

THEODORO JUNIOR, Humberto; NUNES, Dierle; BAHIA, Alexandre Melo Franco. Litigância de Interesse Público e Execução comparticipada de políticas públicas. Revista de Processo, v. 224, out. 2013. 
VERBICARO, Dennis. Consumo e Cidadania: identificando os espaços políticos de atuação qualificada do consumidor. Rio de Janeiro: Lumen Juris, 2017.

VERBICARO, Dennis; COSTA, Emanuelle Dias. A atuação qualitativa das associações de defesa do consumidor como expressão de uma democracia deliberativa: mapeamento da atuação judicial e extrajudicial no âmbito do Estado do Pará. Revista Eletrônica Direito e Sociedade - Redes, Canoas, v. 6, n. 2. 2018.

VERBICARO, Dennis; OHANA. Gabriela. O Reconhecimento do Dano Moral Coletivo Consumerista diante da prática empresarial do Bluewashing. Revista de Direito do Consumidor. São Paulo, v. 129, maio/jun. 2020.

VERBICARO, Dennis; SILVA, João Vitor Penna; LEAL, Pastora. O mito da indústria do dano moral e a banalização da proteção jurídica do consumidor pelo judiciário brasileiro. Revista de Direito do Consumidor, São Paulo, v. 114, nov./dez. 2017.

VERBICARO, Dennis; VIERA, Janaina do Nascimento. A hipervulnerabilidade do turista e a responsabilidade das plataformas digitais: Uma análise a partir da perspectiva da economia colaborativa. Revista de Direito do Consumidor, São Paulo, v. 127, jan./fev. 2020.

VERBICARO, Loiane Prado. Judicialização da política, ativismo e discricionariedade judicial. Rio de Janeiro: Lumen Juris, 2017.

VITORELLI, Edilson. O Devido processo legal coletivo: representação, participação e efetividade da tutela jurisdicional. Tese (Doutorado em Direito). Universidade Federal do Paraná. Curitiba, Paraná, 2015.

VITORELLI, Edilson. Raciocínios probabilísticos implícitos e o papel do estatístico na analise probatória. Revista de processo. v. 297, nov. 2019a.

VITORELLI, Edilson. Decisão Judicial por métodos estatísticos: Novos horizontes para causas repetitivas? Revista de processo. v. 298, dez. 2019b.

ZAK, Paul. A molécula da moralidade: as surpreendentes descobertas sobre a substancia que desperta o melhor em nós. Rio de janeiro: Elsevier, 2012.

ZAVASKI, Teori Albino. Processo coletivo: tutela dos direitos coletivos e tutela coletiva dos direitos. 2. ed. São Paulo: RT, 2007. 